\title{
Plural de intelectual, Mário Pedrosa
}

Josnei Di Carlo ${ }^{1}$

Rodrigo Czajka²

Nascido em 25 de abril de 1900 e falecido em o5 de novembro de 1981, Mário Pedrosa é um filho do século XX. Não por mero acaso cronológico, mas por ser um agente histórico, procurando intervir no processo social e, por conta de seu relativo protagonismo, sofrendo os sabores e dissabores da era dos extremos. Se na juventude fez parte das primeiras gerações comunistas - por ter se filiado ao Partido Comunista Brasileiro (PCB) em 1925, rompendo cerca de quatro anos depois ao aproximar-se da Oposição de Esquerda -, na velhice foi o primeiro a assinar o Manifesto de Lançamento do Partido dos Trabalhadores (PT), em 10 de fevereiro de 1980. Se na casa dos trinta anos foi para o exílio em razão do Golpe de 1937, nem bem completara setenta teve de exilar-se novamente pelo fato de os militares decretarem sua prisão preventiva em 1970, auge da repressão política da ditadura militar.

No olho do furacão, formou-se em Direito em 1923 e passou a exercer o jornalismo em 1924, algo comum nos círculos intelectuais da época3. Voltando de seu primeiro exílio em 1945 como jornalista do Correio da Manhã, logo em seguida passaria a ser reconhecido como uma autoridade em arte moderna, consoante à criação de sua coluna "Artes Plásticas" no diário carioca em 1946. Profissionaliza-se, portanto, como crítico de arte, passando a ser contratado pelos jornais como colunista cultural - apesar de em períodos bem demarcados também escrever sobre política - até 1968, quando fecha sua fase mais produtiva intelectualmente (DI CARLO, 2019b).

\footnotetext{
${ }^{1}$ Pós-doutorando no Programa de Pós-Graduação em Sociologia e Ciência Política da Universidade Federal de Santa Catarina (PPGSP/UFSC), com bolsa do Conselho Nacional de Desenvolvimento Científico e Tecnológico (CNPq).

2 Professor do Departamento de Sociologia e do Programa de Pós-Graduação em Sociologia da Universidade Federal do Paraná (UFPR).

3 Apesar de poucos trabalhos serem sobre a trajetória pedrosiana no todo, indiquemos alguns que procuraram sistematizá-la. Enquanto Pedroso e Vasquez (1992) e Pedrosa (2019) fazem uma cronologia, Elia (1982) e Andrade (2014) apresentam uma síntese. Se Karepovs (2017) faz uma biografia política de Pedrosa, Arantes (1991) faz um itinerário dele enquanto crítico de arte e Di Carlo (2019a) preocupa-se em apresentar suas formas de intervenção na esfera pública. Por fim, Marques Neto (1993) expõe sua formação política entre os anos 1920 e 1930.
} 
Apesar de telegráfico, esse recorte evidencia os campos em que Pedrosa se consagrou: no artístico e no político, podendo privilegiar um em detrimento de outro, devido às condições objetivas e subjetivas, embora sempre exercendo suas atividades intelectuais em ambos. Enquanto intelectual multifacetado, a forma de sua apreensão pelos pesquisadores das ciências humanas, premidos pela especialização acadêmica, torna-se um problema metodológico para pensarmos a formação de uma agenda de pesquisa sobre pensadores de mesma linhagem e os limites da categorização de intelectuais marcados pelo caráter intermitente de sua intervenção na esfera pública, em função de mudanças sociais aceleradas - em menor medida, por afetar a todos indistintamente - e da repressão política recorrente - central para os que procuraram se colocar ao lado dos vencidos.

Comecemos, então, pela forma como a sociologia analisa o tema dos intelectuais, passemos pela agenda de pesquisa sobre Pedrosa, para indicar como ele é construído como intelectual, para finalizarmos o texto com uma síntese dos artigos que compõem o dossiê Mário Pedrosa, 120 Anos, da revista Sociologias Plurais, vinculada ao Programa de Pós-Graduação em Sociologia da Universidade Federal do Paraná (PGSocio/UFPR), em seu primeiro número de seu sétimo volume.

\section{O lugar dos intelectuais nas análises sociológicas}

Há uma larga tradição de estudos sobre o papel desempenhado pelos intelectuais nas sociedades ocidentais e de que forma suas intervenções públicas resultaram num conjunto significativo de transformações políticas e culturais.

Desde a consideração do caso clássico de Émile Zola e sua carta ao presidente da França sobre o caso Dreyfus, passando pelo engajamento de Jean-Paul Sartre ao movimento comunista ou até mesmo às missivas de Norman Mailer endereçadas a Jimmy Carter a questionar a Guerra do Vietnã, a disposição dos intelectuais em intervir e contribuir com o debate sobre os rumos da vida social tornou-se ponto pacífico quando nos referimos à noção mais ampla de intelectual. Sobretudo, quando estes debates assumem proporções grandiloquentes e ganham as páginas dos jornais, as colunas de análise e crítica culturais ou nos espaços de representação intelectual por 
excelência. Essa tradição fundou, de certa forma, um modo de compreender e asseverar a figura do intelectual como um sujeito que não apenas produzia uma leitura, uma interpretação e, por conseguinte, uma teoria sobre a realidade, mas aquele capaz de condensar em si e na sua "teoria" uma visão de mundo atinente à conjuntura; que permita abrir clareiras em meio à escuridão perpetrada por opinião anticientíficas. Até porque, como nos faz lembrar Said (2005, p. 10), "uma das tarefas do intelectual reside no esforço em derrubar os estereótipos e as categorias redutoras que tanto limitam o pensamento humano e a comunicação".

Entretanto, essa representação do intelectual há muito perdeu seu significado (ou importância?). Há vários fatores que podem explicar o ocaso da figura do intelectual público como, por exemplo, o declínio da dimensão utópica entre os intelectuais (aqui compreendidos como professores, escritores, poetas jornalistas, produtores/mediadores culturais, entre outros). Jacoby (2001, p. 140) descreve, inclusive, que essa mudança precisa ser compreendida nos termos de um debate que levem em consideração a linguagem e a reflexão que resultam de um dado contexto histórico e, pode-se dizer, de certa determinação econômica para além do próprio "campo" intelectual:

[...] Ninguém transcende completamente a história. Sobreviver no século XVIII como escritor independente maquinando seus próprios projetos é algo que afeta a prosa e o pensamento em determinado sentido; atuar no século XX como professor, preparando conferências acadêmicas e ensaios eruditos, deverá influenciá-los em outro sentido [...].

Assim, é correto afirmar que a profissionalização do intelectual o levou a uma condição sine qua non, a um processo que resultou numa variedade de formas de apreensão do fenômeno intelectual, tanto na esfera pública como na privada. Se aquela mudança de função política da esfera pública identificada por Habermas (cf. 2014, p. 185-237), em 1961, já não condizia com os elementos estruturais que fundaram um tipo de sociabilidade inerente à formação da burguesia letrada na passagem do séc. XVIII para o XIX, no século XX elas deixaram de existir. Mais que isso: para se compreender como aquelas estruturas sofreram tais transformações, foi preciso identificar nos 
intelectuais o principal termômetro da profusão e da profundidade destas transformações.

Portanto, a ação intelectual, bem como as relações sociais empreendidas por ele na construção de sua intervenção ou ainda a justificação da sua presença na vida pública diversificou-se a medida que também diversificavam-se os públicos. Nesse sentido, as investigações que se fizeram no decorrer do século XX sobre os itinerários de intelectuais e artistas, a exemplo de As Regras da Arte (BOURDIEU, 1996) ou de As Palavras e as Coisas (FOUCAULT, 1994), demonstraram a intensa pulverização do tema "intelectuais", mas também reverberaram como este objeto refletia as condições históricas da sua própria investigação. Até porque se nos centros de pesquisa europeus ou norte-americanos o tema dos intelectuais era carregado de elementos concernentes à formação de cada “escola” ou “movimento", em países de economia periférica a presença dos intelectuais e os estudos daí decorrentes deram-se noutra chave. Tal como afirmava Wright Mills (2017, p. 22),

[...] o conhecimento é uma escolha tanto de um modo de vida quanto de uma carreira; quer saiba ou não, o trabalhador intelectual forma-se a si próprio à medida que trabalha para o aperfeiçoamento de seu ofício; [...] isto significa que deve aprender a usar a sua experiência de vida em seu trabalho intelectual examiná-la e interpretá-la continuamente.

Diferentemente das rotinas de pesquisa que seguem as agendas e linhas de trabalho de grupos consolidados - e aqui nos referimos à condição daqueles indivíduos que se profissionalizaram a ponto de perderem seus vínculos públicos com a atividade intelectual - o "artesanato intelectual" proposto por Wright Mills recobra certa mentalidade, em especial aquela cindida que representa a concomitância do sujeito de letras que não passa incólume às experiências cotidianas e, mais que isso, as torna parte de sua elaboração crítica - seria esta uma forma de reconstruir uma perspectiva pública da intervenção intelectual?

Via de regra essa é disposição que temos ao analisarmos a presença dos intelectuais nas sociedades latino-americanas. A noção de cidade letrada, proposta por Angel Rama, sobretudo quando considerado o aspecto da modernização como fator fundamental também da organização dos intelectuais. Segundo Rama (1985, p. 82-83), 
Teve uma multiplicidade de causas, entre as quais se inclui um sentimento de frustração e impotência [...] e uma alta produção de intelectuais que não se adequava às expectativas da sociedade, reais mas menos dinâmicas do que aparentavam, incapazes, portanto, de absorver essas capacidades e forçandoas ao translado para países desenvolvidos. Mas esse pensamento não deixou de amoldar-se dentro de estruturas culturais que, ainda que se apresentassem modernizadas, repetiam as normas tradicionais. Certa vez, Vaz Ferreira assinalou que os que não haviam chegado a tempo de ser positivistas, foram marxistas, apontando, mais do que a uma crítica de qualquer uma das duas filosofias, para as adaptações que haviam experimentado em terras americanas as doutrinas recebidas do exterior: obrigatoriamente se ajustaram a tendências e comportamentos intelectuais elaborados pelas vigorosas tradições internas. [...] Foi assim que a dissidência crítica continuou compartilhando os enraizados princípios da cidade letrada, sobretudo o que a associava ao exercício do poder.

É, pois, muito próxima dessa compreensão elaborada por Rama que autores como o peruano José Carlos Mariátegui ou mesmo o italiano Antonio Gramsci serão lidos e interpretados à luz da estrutura colonial, sem desconsiderar o aspecto da modernização na América Latina no decorrer do século XX. Interessante notar também que a recepção destes intelectuais está associada a uma possibilidade de construção de certa emancipação das classes subalternizadas no curso do desenvolvimento capitalista, ao mesmo tempo em que se instiga o desenvolvimento de um marxismo com enfoque na questão colonial.

No caso do Brasil, especificamente, há vários autores que operaram nessa chave interpretativa, a exemplo de Caio Prado Júnior, Florestan Fernandes e o próprio Pedrosa. Dado a forma de este intervir na esfera pública como intelectual - ora como crítico de arte, ora como pensador político - pode ser tomado como um caso exemplar para refletirmos como se constitui uma agenda de pesquisa sobre intelectuais. Assim, o mercado editorial e a academia são duas instâncias que reposicionam constantemente as ideias de um pensador, com cada contexto dando os limites para sua obra ser lida e para seu reconhecimento a posteriori. Em síntese, como os pesquisadores constroem um intelectual quando ele é plural, como era Pedrosa? 


\section{O lugar de Pedrosa nas pesquisas acadêmicas}

O levantamento de dissertações e teses ${ }^{4}$ é uma base de apoio para produzir uma reflexão metodológica sobre o problema formulado acima, que também pode ser apresentado em outros termos; a saber, como um intelectual entra na agenda de pesquisa? Pedrosa pode ser tomado como um objeto paradigmático por várias razões. Por não ser um intelectual acadêmico, não há uma compartimentação a priori de sua produção intelectual. Por conseguinte, sua obra encontra-se em dois campos distintos - o artístico e o político - por ser mais produto das vicissitudes históricas e sociais do que dos imperativos científicos e departamentais. Pedrosa é um pensador que não objetivou um sistema, mas que suas ideias entrassem no fluxo do tempo presente para mudar o curso das artes e da política. Não é o maior êxito em um campo em relação ao outro que sustenta a formação de uma agenda de pesquisa sobre ele, é, ao contrário, sua relativa marginalidade em ambos em vida, fazendo com que a consagração de sua obra ainda esteja em construção pelo mercado editorial e pela academia.

Pedrosa entra na agenda de pesquisa um ano após sua morte. Entre 1982 e 2020, foram defendidas 26 dissertações e dez teses sobre sua obra. O fato de estarem distribuídas em 22 programas de pós-graduação diferentes indica mais uma dispersão departamental - produto do regramento dos órgãos de fomento, cuja corrida dos departamentos pelos recursos financeiros leva a uma maior fragmentação institucional - do que consequência de um objeto a criar uma dificuldade de compreensão sistemática. Assim, ao organizar os dados por área de conhecimento, o total reduz cerca de 60\%. A produção acadêmica pedrosiana no Gráfico 1 foi dividida em História, Artes, Ciências Sociais, Filosofia e Outras (Arquitetura e Urbanismo, Educação, Psicologia e Letras) $)^{5}$.

4 Di Carlo (2017) realizou um levantamento até 2016 e fizemos outro dos anos subsequentes monitorando o alerta do Google e do Google Acadêmico para os termos "Mário Pedrosa" e "Pedrosa, Mário". Também consultamos o Currículo Lattes e as referências bibliográficas das novas dissertações e teses apresentadas após 2016.

${ }^{5}$ Os programas de pós-graduação por áreas de conhecimento são: 1) História, História Social e História Social da Cultura foram classificados como História; 2) Artes, Artes Visuais, Interunidades em Estética e História da Arte, Arte e Cultura Contemporânea, Arte e Produção Simbólica e Estética e História da Arte, como Artes; 3) Ciência Política, Sociologia e Antropologia, Antropologia Social, Ciências Sociais, Sociologia e Ciência Política e Sociologia, como Ciências Sociais; 4) Filosofia, como Filosofia; 5) 


\section{Gráfico 1: Dissertações e teses sobre Mário Pedrosa divididas por área de conhecimento (1982-2020)}

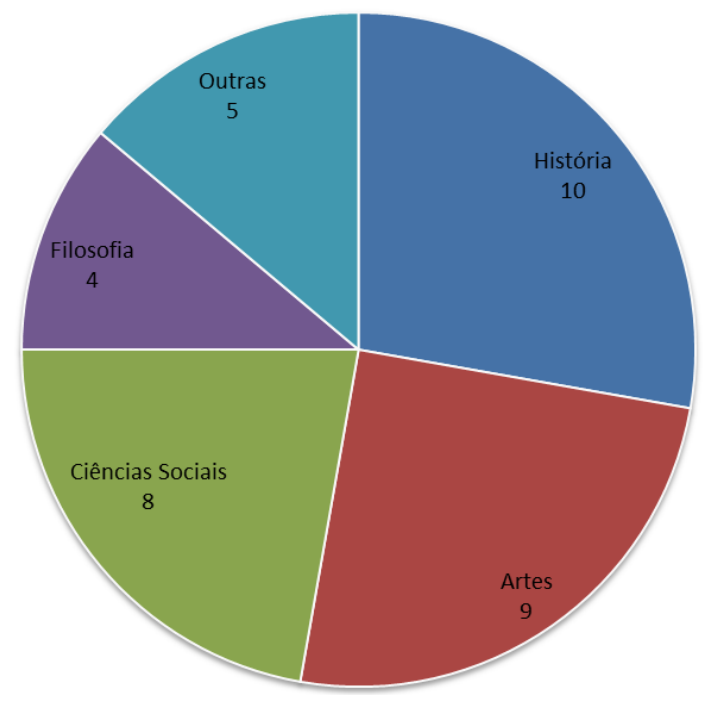

Fonte: elaborado com base em levantamento de Di Carlo (2017) e dos autores

De acordo com os dados, $75 \%$ das dissertações e teses sobre Pedrosa estão concentradas em três áreas de conhecimento. Enquanto Filosofia concentra três trabalhos acadêmicos de 1982 a 1992, História, Artes e Ciências Sociais uma cada ${ }^{6}$. A obra pedrosiana, portanto, entra na agenda de pesquisa das áreas predominantes posteriormente. Também passa a ser pesquisada por outras. Duas das cinco dissertações e teses agrupadas em "Outras” no Gráfico 1 são da área de Arquitetura e Urbanismo, com ambas apresentadas nos últimos três anos. Os movimentos podem indicar que a academia se aproxima de Pedrosa conforme cada contexto o tipifica. Em termos concretos, tornou-se um pensador da arquitetura a partir do momento em que passou a ser reconhecido como tal. Guilherme Wisnik é responsável pela organização, prefácio e notas dos textos arquitetônicos pedrosianos lançado pela Cosac Naify em 2015 (PEDROSA, 2015a). Arquitetura: Ensaios Críticos é o primeiro livro exclusivo sobre arquitetura de Pedrosa.

Arquitetura e Urbanismo, como Arquitetura e Urbanismo; 7) Psicologia Social, como Psicologia; 6) Educação, como Educação; 8) Teoria Literária e Literatura Comparada, como Letras.

${ }^{6}$ Visando a transparência dos dados, o levantamento é apresentado em forma de uma tabela no apêndice ao fim deste artigo. 
É “a vitória de seus fracassos”, na feliz expressão do título de uma entrevista sua dada ao Pasquim (GULLAR et al., 1978), que desperta o interesse dos pesquisadores por Pedrosa. No processo, incompleto e irregular, foram produzidos 36 trabalhos acadêmicos sobre ele no total. Para um crítico de arte, com um círculo restrito de leitores - apesar de suas colunas serem publicadas nos principais órgãos de imprensa entre 1946 e 1968 -, e um pensador político de esquerda opositor do PCB e do stalinismo, o número é meritório. Embora suas posições colocassem-no à margem, procurou conduzir-se ao centro dos debates culturais, com o reconhecimento vindo pelas vanguardas artísticas que se sucederam no Brasil entre os anos 1940 e 1960 (FORMIGA, 2014; PEDROSO, 1992), e político, pagando o preço por suas alianças táticas com os liberais no mesmo período (DI CARLO, 2019b; MARTINS, 2001).

A segmentação anual das 36 dissertações e teses - como pode ser verificada no Gráfico 2 - permite afirmar que a agenda de pesquisa pedrosiana tem dois ciclos bem demarcados. O primeiro inicia-se em 1982 e encerra-se em 200o; o segundo, por sua vez, começa em 2001 e segue até hoje. O centenário de nascimento de Pedrosa comemorado em 2000 - cujo evento mais significativo foi o seminário Mário Pedrosa e o Brasil: 100 Anos de Arte e Política, organizado pela Fundação Perseu Abramo e pelo Centro de Documentação e Memória da Universidade Estadual Paulista (CEDEM/UNESP), por suas conferências terem sido publicadas em livro (MARQUES NETO, 2001) - é o marco a dividir os dois ciclos. Mas o alicerce do segundo vinha sendo criado no primeiro, embora pelo mercado editorial (DI CARLO, 2017), como no exemplo de Arquitetura e Urbanismo das áreas de conhecimento.

Em 1991, Otília Beatriz Fiori Arantes publicou Mário Pedrosa - Itinerário Crítico, pela Scritta Editorial. No livro, analisa a crítica de arte de Pedrosa. Começa nos anos 1930, quando ele escreveu seus primeiros textos sobre arte, mais como diletante do que um especialista, avança para suas colunas culturais de 1946 a 1968, onde ele se consolidou como crítico de arte na imprensa, e encerra na década seguinte, com ele afastando-se gradativamente da crítica de arte (ARANTES, 1991). Em um período posterior imediato, Arantes é responsável pela maior iniciativa editorial de publicação 
da obra pedrosiana até hoje7. Entre 1995 a 2000, organizou uma antologia em quatro volumes da crítica de arte de Pedrosa para a EDUSP (PEDROSA, 1995, 1996, 1998, 200o) ${ }^{8}$. Com Mário Pedrosa - Itinerário Crítico cria uma série de problemas para os pesquisadores; com Política das Artes (1995), Forma e Percepção Estética (1996), Acadêmicos e Modernos (1998) e Modernidade Cá e Lá (2000) dispõe fontes para hipóteses serem testados por eles.

\section{Gráfico 2: Dissertações e teses sobre Mário Pedrosa classificadas segundo o campo de sua atuação intelectual analisado, por ano, a partir de 1982}

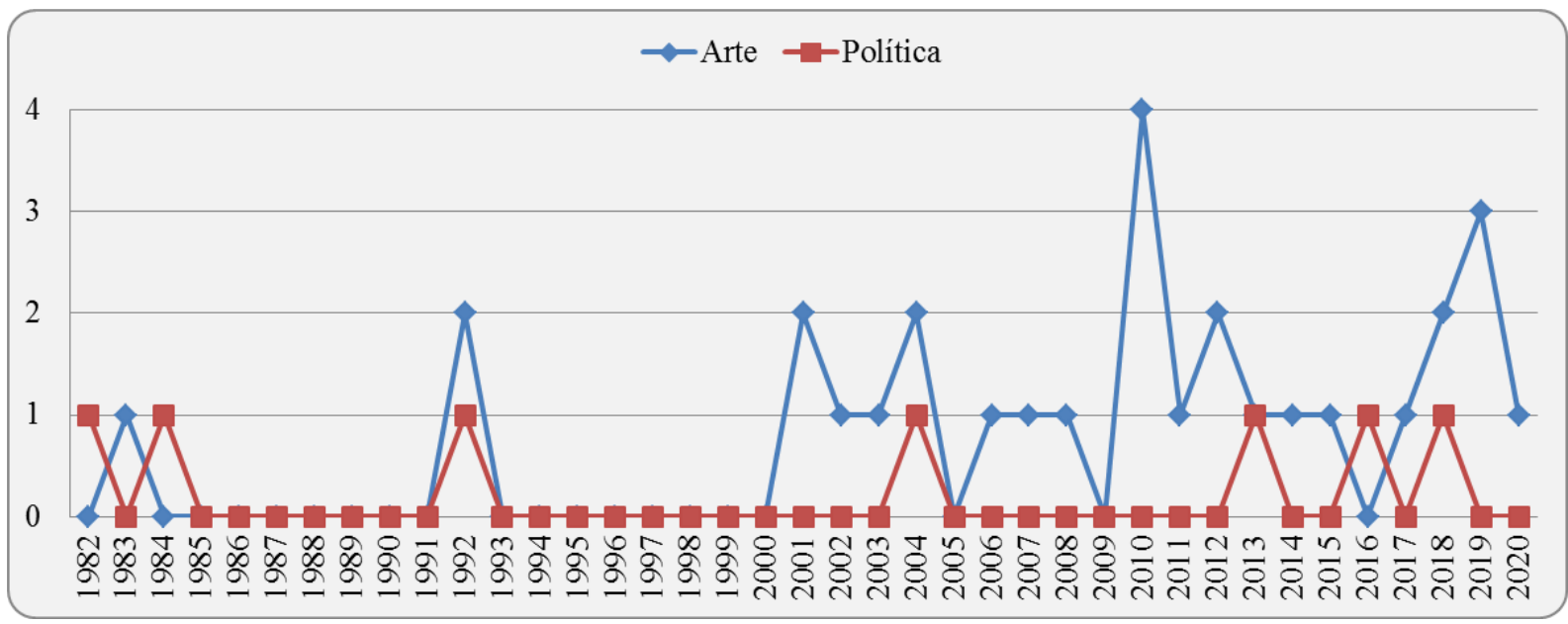

Fonte: elaborado com base em levantamento de Di Carlo (2017) e dos autores

Em uma data comemorativa, os agentes podem articular diversas instituições e suas redes de sociabilidade (cf. FARIA FILHO, 2017) para tornar a obra de um intelectual um documento/monumento (cf. LE GOFF, 1990). Há, porém, um recorte. No caso de Pedrosa, sua agenda de pesquisa estreitou-o mais e mais à sua posição social de crítico de arte. As seis dissertações e teses sobre ele defendidas no primeiro

\footnotetext{
7 Nos anos 2010, a Cosac Naify começou um projeto editorial sobre Pedrosa, chegando a publicar dois volumes da coleção Mário Pedrosa, cuja coordenação estava a cargo de Danis Karepovs, Francisco Alambert, Guilherme Wisnik, Isabel Maria Loureiro, Lorenzo Mammì e Milton Ohata (PEDROSA, 2015a, 2015b). Com a falência da editora em 2015, o projeto foi abortado. Um de seus coordenadores, Alambert, afirmou que a coleção ia ser mais ampla, "quase completa", comparada com a de Arantes (DI CARLO, 2016, p. 255).

${ }^{8}$ Nos quatro volumes foram publicados parte dos setecentos textos de Pedrosa sobre artes reunidos por Arantes (1995, p. 9). O arco temporal deles vai de 1933 a 1980. Di Carlo (2019b), ao fazer um levantamento das colunas pedrosianas de artes e política nos jornais Correio da Manhã, O Estado de $S$. Paulo, Tribuna da Imprensa e Jornal do Brasil entre 1944 e 1968, contabilizou ao todo 1012. Enquanto não houver uma organização sistemática dessa obra, os números sempre serão discrepantes.
} 
ciclo - como o Gráfico 2 demonstra - dividem-se de forma equitativa em relação à sua atuação intelectual no campo artístico e político. No segundo ciclo, não mais, predominando um campo sobre o outro: das trinta, 26 voltam-se para seus textos de arte $(86,66 \%)$ e quatro dedicam-se a seus textos políticos $(13,33 \%)$.

Dado a trajetória de Pedrosa, com a arte e a política galvanizando sua atuação na esfera pública, as pesquisas acadêmicas fazem com que retrospectivamente sua posição social torne-se mais homogênea do que realmente foi em vida. Sua produção jornalística na grande imprensa de 1944 a 1968 tem períodos em que os textos políticos sobrepõem-se aos de arte (DI CARLO, 2019b, p. 272). No mesmo período, fundou o jornal político Vanguarda Socialista, que circulou sob sua direção entre 1945 e 1948, teve militância destacada no Partido Socialista Brasileiro (PSB) de 1946 a 1956, assim por diante. Apesar dos contraexemplos, ao se formar uma agenda de pesquisa consistente da obra pedrosiana no século XXI, a crítica de arte passa a definir seu reconhecimento como intelectual na contemporaneidade.

Assim, das 36 dissertações e teses sobre Pedrosa apenas sete analisam sua obra política (discrepância visível no Gráfico 3). Destas, três pertencem ao primeiro ciclo: duas sobre o Vanguarda Socialista e uma sobre seu rompimento com o PCB e posterior militância no trotskismo. Pelo fato de as duas primeiras terem sido apresentadas na primeira metade dos anos 1980 e a última no começo da década de 1990, certamente os recortes deram-se por causa dos fluxos da transição democrática, marcada pelo fortalecimento dos movimentos populares e pela formação do PT. Para parte da esquerda, o que estava em jogo era um socialismo democrático - tão caro a Pedrosa, especialmente após voltar de seu primeiro exílio em 1945. No primeiro ciclo, portanto, uma parte da produção acadêmica poderia ter inventado outro intelectual; qual seja, de precursor de um socialismo que passou a se identificar com o PT. 
Gráfico 3: Dissertações e teses sobre Mário Pedrosa divididas pelo campo de sua atuação intelectual analisada (1982-2020)

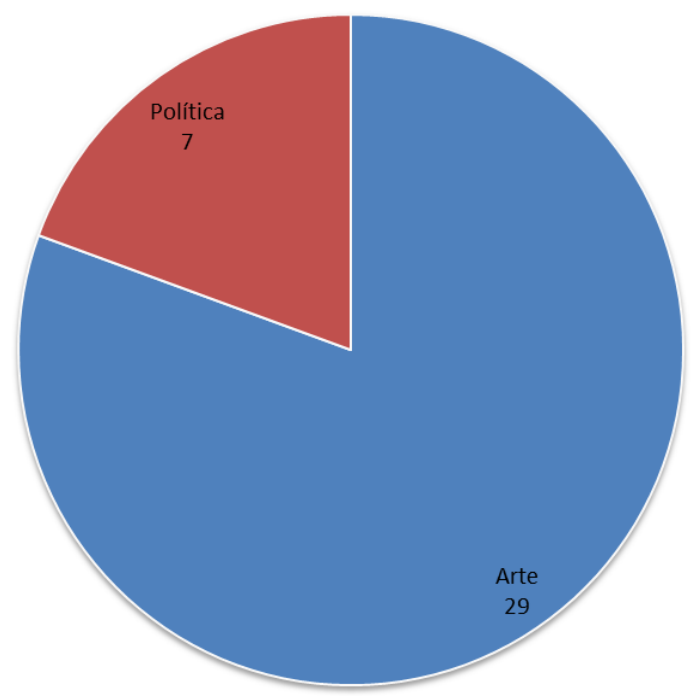

Fonte: elaborado com base em levantamento de Di Carlo (2017) e dos autores

Em seu livro $O P T$, de 2001, André Singer faz um relato sentimental na “Introdução". Após uma descrição objetiva da reunião em que seria lançado o PT, faz uma síntese da trajetória política de Pedrosa até agosto de 1978, quando publica uma carta aberta na Folha de São Paulo admoestando o então presidente do Sindicato dos Metalúrgicos de São Bernardo e Diadema (SP) a criar um partido liderado por trabalhadores. "O velho socialista, que morreria no ano seguinte ao da criação do PT, teve a sorte de viver o suficiente para participar, na qualidade de homenageado, da realização do antigo sonho", conclui (SINGER, 2001, p. 10), “ver surgir, no Brasil, um amplo partido de esquerda dirigido por operários”. Em 28 de outubro de 2002, um dia após as eleições, Luís Inácio Lula da Silva discursa na Avenida Paulista consagrado pelas urnas como presidente da República e afirma: "Eu, hoje, estava lembrando, quando fui votar [...]. Eu lembrava da figura extraordinária de Mário Pedrosa, que também começou junto conosco esta luta" (apud DI CARLO, 2017).

No campo acadêmico, os pesquisadores passariam a circunscrever a posição social de Pedrosa à sua atividade intelectual de crítico de arte. No campo político, Singer, ao escrever uma história do PT, e Lula, ao vincular sua recém-vitória eleitoral a essa história, demonstram que a trajetória do crítico de arte também fornece 
elementos para posicioná-lo como pensador político, em função do que ele representa como ideologia política finalmente erigiu um partido e chegou ao poder central logo após seu centenário de nascimento. Intelectuais acadêmicos de matizes políticas distintas e sem vínculos com o PT e a esquerda, embora com formação políticaintelectual marxista dada entre os anos 1940 e 1950 - como no caso de Oliveiros S. Ferreira e Hélio Jaguaribe -, relacionam-se com a memória pedrosiana de forma similar.

No artigo "A Espada e o Escudo", publicado no Estado de S. Paulo em 13 de março de 1983, Ferreira propõe como método a necessidade de se distinguir o marxismo e o comunismo brasileiros não só para conhecer a história do primeiro melhor quanto para emergir alguns de seus protagonistas relegados ao esquecimento por não fazerem parte da história do segundo. “A história do marxismo no Brasil não se poderá fazer sem a referência obrigatória à figura humana e à atuação intelectual de Mário Pedrosa”, mas, continua Ferreira (1983, p. 14), "a história do Partido Comunista em nada se alterará se a ele não se fizer menção". Em entrevista de 1980, Jaguaribe destaca que foi discípulo de Pedrosa e, por conta disso, participou do PSB a seu lado (MOTA, 1982, p. 170). Dezoito anos depois voltaria ao tema, indicando o período que iniciou sua relação política com o crítico de arte: "tive a influência do marxismo, a partir de uma posição antistalinista. Tive muito contato com Mário Pedrosa, que dirigia a revista [sic] Vanguarda Socialista. Contribuí com vários artigos para essa revista [sic]” (COELHO, 1998). Apesar de destacarem Pedrosa como pensador político, Ferreira e Jaguaribe enfatizam sua contribuição à história do marxismo no Brasil e, indiretamente, para a formação de uma geração de intelectuais críticos ao stalinismo.

\section{Mário Pedrosa, 120 anos, uma síntese}

Dado o exposto, qual intelectual emerge dos artigos do dossiê Mário Pedrosa, 120 Anos, da Sociologias Plurais (PGSocio/UFPR)? Uma reposta unívoca não é o objetivo de um dossiê, mas criar problemas não só para os estudos pedrosianos quanto para alguns campos de pesquisa da sociologia, particularmente o da sociologia dos intelectuais, embora não só. Assim, nosso texto tencionou, de um lado, a pensar o 
lugar dos intelectuais nas análises sociológicas, e, de outro, o lugar de Pedrosa nas pesquisas acadêmicas, para a leitura do dossiê ser frutífera para os pesquisadores de sua obra e para o desenvolvimento científico das ciências humanas, em geral, e da sociologia, em particular.

O dossiê abre com um artigo de Everaldo de Oliveira Andrade. Em "Duas ditaduras e uma só liberdade: Mário Pedrosa, o fascismo colonial e o bonapartismo militar", faz uma análise da produção intelectual pedrosiana dos anos 1930 e 1960, mais especificamente no período pré-Estado Novo e da ditadura militar. Nos dois processos, lembra o autor, Pedrosa fez uso dos conceitos marxistas de bonapartismo e desenvolvimento desigual e combinado para produzir uma interpretação original sobre o autoritarismo no Brasil. O próximo artigo, "A trajetória de Mário Pedrosa em suas primeiras apropriações do marxismo (1919-1931)”, afasta-se do método comparativo para centrar no início da trajetória pedrosiana. Ao final dela, Pedrosa publicou "Esboço de Análise da Situação Brasileira” em conjunto com Lívio Xavier. O ensaio em questão - posteriormente conhecido como "Esboço de uma análise da situação econômica e social do Brasil", por assim ter circulado em Na Contracorrente da História, de 1987 (cf. DI CARLO, 2018, p. 163) - tornou-se um pequeno clássico sobre a formação social brasileira pela perspectiva do marxismo, sendo a principal fonte da autora do artigo Juliana Rodrigues Alves.

Nos dois primeiros artigos, a obra pedrosiana investigada é a política. Mas o terceiro, "Gestalttheorie, Mário Pedrosa y el arte concreto argentino: un capítulo de la historia de la psicologización del estudio de la forma y el color en el arte", foca na crítica de arte de Pedrosa. No caso, María Cecilia Grassi objetiva compreender como ele articulou a teoria da Gestalt - da área da psicologia - com as artes. Compreensão necessária para indicar a circulação de suas ideias entre os artistas concretos da Argentina entre os anos 1940 e 1950. O quarto artigo, em uma tentativa de relacionar arte e política em Pedrosa, avança para a década seguinte. Em "As relações entre arte e política na ditadura militar brasileira”, Luis Claudio Reginato Carvalho recorre a Partilha do Sensível (200o), de Jacques Rancière, para fazer essa relação na obra pedrosiana produzida no contexto da ditadura militar. 
Finalmente, os dois últimos artigos esquadrinham o pensamento museal de Pedrosa. Em um, "Do museu de reproduções ao Museu das Origens: reflexões sobre projetos institucionais de Mário Pedrosa”, Sabrina Parracho Sant'Anna e Marcelo Ribeiro Vasconcelos, ao investigarem a proposta pedrosiana de 1958 para o Museu de Brasília, procuram compreendê-la no interior de um projeto estético maior, recorrendo a comparações com o Museu da Solidariedade - gerido por Pedrosa durante seu exílio no Chile (1970-1973) - e o Museu das Origens - idealizado por ele poucos anos depois de voltar do exílio em 1977. O outro artigo, "O incêndio do MAM-RJ e as respostas de Mário Pedrosa às crises artísticas, museológicas e políticas da época”, centra na década de 1970. Nele, André Leal examina duas propostas do crítico de arte - a de exposição de arte indígena Alegria de Viver, Alegria de Criar, prevista para o MAM-RJ antes de seu incêndio em 1978, e o Museu das Origens, idealizado como forma de reconstrução do MAM-RJ - em conjunto com sua atuação à frente do Museu da Solidariedade para também apresentar o projeto estético pedrosiano.

Como se vê, um intelectual como Mário Pedrosa sempre está a abrir flancos de investigação nas mais diversas áreas de conhecimento. Barreto Leite Filho lembra-se de um episódio ilustrativo - possivelmente ocorrido de quando era embaixador de Israel entre 1961 e 1964 - da erudição do amigo. Durante visita à livraria da Universidade Hebraica de Jerusalém, Mário ficou a examinar uma prateleira com "livros sobre as questões mais abstrusas da moderna filosofia científica” e perguntou a Barreto se já os havia lido. A resposta, como era de se esperar, foi de que não por serem distantes de suas leituras de trabalho. "Realmente", começa Mário, conforme relato de Leite Filho (1981, p. 3), “é pena a falta de tempo. Eu me interesso por tudo, desejaria ler tudo”. Que o desejo de Pedrosa seja de todos que o pesquisem e o venham a pesquisar para assim o conhecermos enquanto plural de intelectual. Com os pesquisadores dialogando entre si para que a riqueza de sua obra seja mais bem dimensionada, tornando-se uma fonte para a história de outros Brasis, sobretudo a escrita pelos intelectuais que pagaram o preço por escolherem ficar ao lado dos vencidos, sofrendo com a repressão política constantemente. 


\section{Referências}

ANDRADE, E. O. Mário Pedrosa. In: PERICÁS, L. B.; SECCO, L. (orgs.). Intérpretes do Brasil: clássicos, rebeldes e renegados. São Paulo: Boitempo, 2014. p. 337-355.

ARANTES, O. B. F. Mário Pedrosa: itinerário crítico. SãoPaulo: Scritta Editorial, 1991.

ARANTES, O. B. F. Este volume. In: PEDROSA, M. Política das artes: textos escolhidos I. São Paulo: Edusp, 1995. p. 9-13.

BOURDIEU, P. As regras da arte: gênese e estrutura do campo literário. São Paulo: Companhia das Letras, 1996.

COELHO, M. O Brasil no laboratório de Hélio Jaguaribe. Folha de São Paulo, 15 fev. 1998. Disponível em: <https://www1.folha.uol.com.br/fsp/mais/fs15029809.htm>. Acesso em: 24 jan. 2021.

DI CARLO, J. Política das artes e arte da pesquisa: entrevista com Francisco Alambert. Em Tese, v. 13, n. 1, p. 243-257, jan.-jun. 2016.

Mercado editorial e universidade: Mário Pedrosa, um caso exemplar. Blog Junho, 5 ago. 2017. Disponível em: <http://blogjunho.com.br/mercado-editorial-euniversidade-mario-pedrosa-um-caso-exemplar>. Acesso em: 24 jan. 2021.

Da margem se vê melhor? O autoritarismo no Brasil segundo a Oposição de Esquerda nos anos 1930. Política Hoje, v. 27, n. Especial, p. 162-194, 2018.

Mário Pedrosa. Penápolis: FUNEPE, $2019 a$.

. Vicissitudes do intelectual público: um estudo de caso sobre Mário Pedrosa (1944-1968). Ciências Sociais Unisinos, v. 55, n. 2, p. 265-275, mai.-ago. 2019b.

ELIA, R. Mário Pedrosa (1900-1981): anotações sobre sua trajetória intelectual. Revista Brasileira de História, v. 2, n. 4, p. 259-264, set. 1982.

FARIA FILHO, L. M. de. Edição e sociabilidades intelectuais: a publicação das obras completas de Rui Barbosa (1930-1949). Belo Horizonte: Autêntica; UFMG, 2017.

FERREIRA, O. S. A espada e o escudo. O Estado de S. Paulo, p. 14-15, ano III, n. 144, 13 mar. 1983.

FORMIGA, T. S. À espera da hora plástica: o percurso de Mário Pedrosa na crítica de arte brasileira. Tese - Rio de Janeiro: Universidade Federal do Rio de Janeiro, 2014. 
FOUCAULT, M. As palavras e as coisas: uma arqueologia das ciências humanas. São Paulo: Martins Fontes, 1994.

GULLAR, F. et al. Mário Pedrosa e a vitória dos seus fracassos. Pasquim, p. 4-14, n. 467, $23-29$ jun. 1978.

HABERMAS, J. Mudança estrutural da esfera pública: investigações sobre uma categoria da sociedade burguesa. São Paulo: Unesp, 2014.

JACOBY, R. O fim da utopia: política e cultura na era da apatia. Rio de Janeiro: Record, 2001.

KAREPOVS, D. Pas de politique Mariô! Mário Pedrosa e a política. Cotia: Ateliê Editorial; São Paulo: Fundação Perseu Abramo, 2017.

LE GOFF, J. Documento/monumento. In: História e memória. Campinas: Unicamp, 1990. p. 535-549.

LEITE FILHO, B. O mestre morto. Folha de São Paulo, n. 19212, p. 3 (“Opinião”), 14 nov. 1981.

MARQUES NETO, J. C. Solidão revolucionária: Mário Pedrosa e as origens do trotskismo no Brasil. São Paulo: Paz e Terra, 1993.

(org.). Mário Pedrosa e o Brasil. São Paulo: Fundação Perseu Abramo, 2001.

MARTINS, L. A utopia como modo de vida: fragmentos de lembrança de Mário Pedrosa. In: MARQUES NETO, J. C. (orgs.). Mário Pedrosa e o Brasil. São Paulo: Fundação Perseu Abramo, 2001. p. 29-41.

MOTA, L. D. (org.). A classe média é o pêndulo do sistema político brasileiro. In: A história vivida: entrevistas. São Paulo: O Estado de S. Paulo, 1982. v. 3. p. 167-202.

PEDROSA, M. Política das artes: textos escolhidos I. São Paulo: Edusp, 1995. . Forma e percepção estética: textos escolhidos II. São Paulo: Edusp, 1996. Acadêmicos e modernos: textos escolhidos III. São Paulo: Edusp, 1998. Modernidade cá e lá: textos escolhidos IV. São Paulo: Edusp, 2000. Arquitetura: ensaios críticos. São Paulo: Cosac Naify, 2015a. Arte: ensaios. São Paulo: Cosac Naify, 2015b. 
PEDROSA, Q. Mário Pedrosa, uma cronologia. In: PUCU, I.; VILLAS BÔAS, G.; PEDROSA, Q. (orgs.). Mário Pedrosa, atual. Rio de Janeiro: Instituto Odeon, 2019. p. 7-39.

PEDROSO, F. A abstração e a reflexão: Mário Pedrosa, o crítico como revolucionário. Dissertação - Rio de Janeiro: Universidade Federal do Rio de Janeiro, 1992.

; VASQUEZ, P. Cronologia. In: PEDROSO, F. (orgs). Mário Pedrosa: arte, revolução, reflexão. Porto Alegre: Centro Cultural Banco do Brasil, 1992. p. 49-78.

RAMA, Á. A cidade das letras. São Paulo: Brasiliense, 1985.

SAID, E. W. Representações do intelectual: as conferências Reith de 1993. São Paulo: Companhia das Letras, 2005.

SINGER, A. O PT. São Paulo: Publifolha, 2001.

WRIGHT MILLS, C. Sobre o artesanato intelectual e outros ensaios. Rio de Janeiro: Zahar, 2017. 


\section{Apêndice A - Dissertações e teses sobre Mário Pedrosa (1982-2020)9}

\begin{tabular}{|c|c|c|c|c|c|c|c|c|}
\hline Item & Ano & Título & Autoria & IES & UF & Programa & Nível & Orientação \\
\hline 1 & 1982 & $\begin{array}{l}\text { Vanguarda Socialista: a busca de um caminho } \\
\text { independente }\end{array}$ & $\begin{array}{c}\text { Gina Guelman } \\
\text { Gomes Machado }\end{array}$ & USP & SP & $\begin{array}{l}\text { Ciência } \\
\text { Política }\end{array}$ & Me. & $\begin{array}{l}\text { Oliveiros S. } \\
\text { Ferreira }\end{array}$ \\
\hline 2 & 1983 & Mário Pedrosa e a morte da crítica de arte & Maria José Justino & PUC & SP & Filosofia & Me. & $\begin{array}{l}\text { Bento Prado } \\
\text { Júnior }\end{array}$ \\
\hline 3 & 1984 & $\begin{array}{l}\text { Vanguarda Socialista (1945-1948): um episódio do } \\
\text { ecletismo na história do marxismo brasileiro }\end{array}$ & Isabel Loureiro & USP & SP & Filosofia & Me. & Marilena Chauí \\
\hline 4 & 1992 & $\begin{array}{c}\text { O abstracionismo geométrico na concepção de Mário } \\
\text { Pedrosa: a relação com o desenvolvimento }\end{array}$ & $\begin{array}{l}\text { Miriam Ida } \\
\text { Gerchmann }\end{array}$ & PUC & RS & História & Me. & $\begin{array}{l}\text { Maria Lúcia Bastos } \\
\text { Kern }\end{array}$ \\
\hline 5 & 1992 & $\begin{array}{c}\text { A abstração e a reflexão: Mário Pedrosa, o crítico como } \\
\text { revolucionário }\end{array}$ & Franklin Pedroso & UFRJ & RJ & Artes Visuais & Me. & $\begin{array}{l}\text { Guilherme Sias } \\
\text { Barbosa }\end{array}$ \\
\hline 6 & 1992 & $\begin{array}{c}\text { A revolução solitária: Mário Pedrosa e as origens do } \\
\text { trotskismo no Brasil }\end{array}$ & $\begin{array}{l}\text { José Castilho } \\
\text { Marques Neto }\end{array}$ & USP & SP & Filosofia & Dr. & $\begin{array}{l}\text { Maria Sylvia de } \\
\text { Carvalho Franco }\end{array}$ \\
\hline 7 & 2001 & Botânica no asfalto: as lições do militante Mário Pedrosa & Fabiana Werneck & PUC & $\mathrm{RJ}$ & História & Me. & $\begin{array}{l}\text { Marcelo Gantus } \\
\text { Jasmin }\end{array}$ \\
\hline 8 & 2001 & $\begin{array}{c}\text { Mário Pedrosa e Ferreira Gullar: sobre o ideário da crítica } \\
\text { de arte nos anos } 50 \text { e } 60\end{array}$ & Marcelo Mari & USP & SP & $\begin{array}{c}\text { Arte e } \\
\text { Produção } \\
\text { Simbólica } \\
\end{array}$ & Me. & $\begin{array}{c}\text { Sílvia Miranda } \\
\text { Meira }\end{array}$ \\
\hline 9 & 2002 & Mário Pedrosa, ideólogo de Brasília & $\begin{array}{l}\text { João Henrique } \\
\text { Santos }\end{array}$ & Unesp & SP & História & Me. & $\begin{array}{l}\text { Carlos Eduardo } \\
\text { Jordão Machado }\end{array}$ \\
\hline 10 & 2003 & $\begin{array}{l}\text { Intelectual e artista na Era Vargas: Mário Pedrosa e } \\
\text { Cândido Portinari e suas relações com o poder }\end{array}$ & $\begin{array}{l}\text { Lilian Alcântara } \\
\text { Soares }\end{array}$ & UFPR & PR & História Social & Me. & $\begin{array}{l}\text { Helenice } \\
\text { Rodrigues }\end{array}$ \\
\hline 11 & 2004 & $\begin{array}{c}\text { O antídoto do mal: sobre a arte e loucura, Mário Pedrosa } \\
\text { e Nise da Silveira }\end{array}$ & $\begin{array}{l}\text { Gustavo Henrique } \\
\text { Dionísio }\end{array}$ & USP & SP & $\begin{array}{l}\text { Psicologia } \\
\text { Social }\end{array}$ & Me. & $\begin{array}{l}\text { João Augusto } \\
\text { Frayze-Pereira }\end{array}$ \\
\hline 12 & 2004 & $\begin{array}{c}\text { Mário Pedrosa e o estado bonapartista militarizado no } \\
\text { Brasil de } 1964\end{array}$ & $\begin{array}{l}\text { Dirlene de Jesus } \\
\text { Pereira Rocha }\end{array}$ & UEL & PR & $\begin{array}{l}\text { Ciências } \\
\text { Sociais }\end{array}$ & Me. & $\begin{array}{l}\text { Pedro Roberto } \\
\text { Ferreira }\end{array}$ \\
\hline 13 & 2004 & Estética e política em Mário Pedrosa (1930-195o) & Marcelo Mari & USP & SP & Filosofia & Dr. & Celso Favaretto \\
\hline
\end{tabular}

9 Elaborado com base em levantamento de Di Carlo (2017) e dos autores. 


\begin{tabular}{|c|c|c|c|c|c|c|c|c|}
\hline 14 & 2006 & $\begin{array}{l}\text { A contemporaneidade das contribuições críticas de Mário } \\
\text { Pedrosa }\end{array}$ & Juana Nunes Pereira & UERJ & $\mathrm{RJ}$ & Artes & Me. & $\begin{array}{l}\text { Sheila Gabo } \\
\text { Geraldo }\end{array}$ \\
\hline 15 & 2007 & $\begin{array}{c}\text { A arte informal e os limites do discurso crítico moderno } \\
\text { em Antônio Bento e Mário Pedrosa, no final da década de } \\
1950\end{array}$ & Ana Paula França & UFRJ & $\mathrm{RJ}$ & Artes Visuais & Me. & $\begin{array}{l}\text { Maria Luisa Luz } \\
\text { Távora }\end{array}$ \\
\hline 16 & 2008 & $\begin{array}{c}\text { A singularidade como regime de grandeza: nação e } \\
\text { indivíduo como valores no discurso artístico brasileiro }\end{array}$ & Patrícia Reinheimer & UFRJ & $\mathrm{RJ}$ & $\begin{array}{l}\text { Antropologia } \\
\text { Social }\end{array}$ & Dr. & Giralda Seyferth \\
\hline 17 & 2010 & $\begin{array}{l}\text { A "utopia estético-política" da arte: a arte como parte da } \\
\text { estratégia revolucionária na obra de Mário Pedrosa }\end{array}$ & Larissa Costard & UFF & $\mathrm{RJ}$ & História & Me. & Adriana Facina \\
\hline 18 & 2010 & $\begin{array}{c}\text { Diálogos concretos. A crítica de Mário Pedrosa, } \\
\text { Waldemar Cordeiro e Ferreira Gullar }\end{array}$ & $\begin{array}{l}\text { Isabela Maria Lyra } \\
\text { Zyro }\end{array}$ & PUC & RJ & $\begin{array}{c}\text { História Social } \\
\text { da Cultura }\end{array}$ & Me. & Ronaldo Brito \\
\hline 19 & 2010 & $\begin{array}{l}\text { Fulguração moderna: a educação pela arte no Museo de } \\
\text { la Solidaridad }\end{array}$ & $\begin{array}{l}\text { Silvia Karina } \\
\text { Nicacio Cáceres }\end{array}$ & PUC & RJ & Educação & Me. & Ralph Ings Bannell \\
\hline 20 & 2010 & $\begin{array}{c}\text { A força transformadora da arte: as contribuições de } \\
\text { Mário Pedrosa para a arte/educação }\end{array}$ & Vera Lucia Pletitsch & UERJ & $\mathrm{RJ}$ & Artes & Me. & Isabela Frade \\
\hline 21 & 2011 & $\begin{array}{c}\text { Os movimentos da sensibilidade: o diálogo entre Mário } \\
\text { Pedrosa e Alexander Calder no projeto construtivo } \\
\text { brasileiro }\end{array}$ & $\begin{array}{l}\text { Bruno Gustavo } \\
\text { Muneratto }\end{array}$ & UNESP & SP & História & Me. & $\begin{array}{l}\text { Carlos Eduardo } \\
\text { Jordão Machado }\end{array}$ \\
\hline 22 & 2012 & $\begin{array}{c}\text { Arte, socialismo e exílio. Formação e atuação de Mário } \\
\text { Pedrosa de } 1930 \text { a } 1950\end{array}$ & $\begin{array}{l}\text { Marcelo Ribeiro } \\
\text { Vasconcelos }\end{array}$ & UFRJ & RJ & $\begin{array}{c}\text { Sociologia e } \\
\text { Antropologia }\end{array}$ & Me. & Glaucia Villas Bôas \\
\hline 23 & 2012 & $\begin{array}{l}\text { Aproximações entre Mário Pedrosa e Gestalt. Crítica e } \\
\text { estética da forma }\end{array}$ & $\begin{array}{l}\text { Gabriela Borges } \\
\text { Abraços }\end{array}$ & USP & SP & $\begin{array}{l}\text { Estética e } \\
\text { História da } \\
\text { Arte }\end{array}$ & Me. & $\begin{array}{l}\text { Lisbeth Rebollo } \\
\text { Gonçalves }\end{array}$ \\
\hline 24 & 2013 & $\begin{array}{l}\text { Quirino Campofiorito e Mário Pedrosa: entre a figuração } \\
\text { e a abstração }\end{array}$ & $\begin{array}{l}\text { Beatriz Pinheiro de } \\
\text { Campos }\end{array}$ & UFJF & MG & História & Me. & Angela Brandão \\
\hline 25 & 2013 & $\begin{array}{c}\text { A interpretação de Mário Pedrosa sobre a Revolução de } \\
1930 \text { e o Golpe de } 1964\end{array}$ & Josnei Di Carlo & UFSCar & SP & $\begin{array}{l}\text { Ciência } \\
\text { Política }\end{array}$ & Me. & Vera Alves Cepêda \\
\hline 26 & 2014 & $\begin{array}{c}\text { À espera da hora plástica: o percurso de Mário Pedrosa } \\
\text { na crítica de arte brasileira }\end{array}$ & $\begin{array}{l}\text { Tarcila Soares } \\
\text { Formiga }\end{array}$ & UFRJ & $\mathrm{RJ}$ & $\begin{array}{l}\text { Sociologia e } \\
\text { Antropologia }\end{array}$ & Dr. & Glaucia Villas Bôas \\
\hline 27 & 2015 & $\begin{array}{l}\text { Mário Pedrosa e a desmistificação da missão francesa de } \\
1816\end{array}$ & $\begin{array}{l}\text { Lucas de Araújo } \\
\text { Barbosa Nunes }\end{array}$ & Unesp & SP & História & Me. & $\begin{array}{l}\text { Carlos Eduardo } \\
\text { Jordão Machado }\end{array}$ \\
\hline 28 & 2016 & $\begin{array}{c}\text { Internacionalismo e nacionalismo em Mário Pedrosa: um } \\
\text { estudo sobre sua obra política (1925-1966) }\end{array}$ & $\begin{array}{c}\text { Fagner Enrique } \\
\text { Fonseca de Oliveira }\end{array}$ & UFG & $\mathrm{GO}$ & História & Me. & David Maciel \\
\hline
\end{tabular}




\begin{tabular}{|c|c|c|c|c|c|c|c|c|}
\hline 29 & 2017 & $\begin{array}{c}\text { Mário Pedrosa e a arquitetura brasileira: autonomia e } \\
\text { síntese das artes }\end{array}$ & $\begin{array}{l}\text { Marcos Faccioli } \\
\text { Gabriel }\end{array}$ & USP & SP & $\begin{array}{l}\text { Arquitetura e } \\
\text { Urbanismo }\end{array}$ & Dr. & $\begin{array}{l}\text { José Tavares } \\
\text { Correia de Lira }\end{array}$ \\
\hline 30 & 2018 & $\begin{array}{l}\text { Mário Pedrosa entre os tupiniquins ou nambás: uma } \\
\text { perspectiva primitivista para a arte pós-moderna }\end{array}$ & Pollyana Quintella & UERJ & RJ & $\begin{array}{l}\text { Arte e Cultura } \\
\text { Contemporân } \\
\text { ea }\end{array}$ & Me. & $\begin{array}{l}\text { Marcelo Gustavo } \\
\text { Lima de Campos }\end{array}$ \\
\hline 31 & 2018 & $\begin{array}{c}\text { O exílio de Mário Pedrosa nos Estados Unidos e os New } \\
\text { York Intellectuals: abstracionismo na barbárie }\end{array}$ & $\begin{array}{c}\text { Marcelo Ribeiro } \\
\text { Vasconcelos }\end{array}$ & Unicamp & SP & Sociologia & Dr. & Renato Ortiz \\
\hline 32 & 2018 & $\begin{array}{c}\text { Intelectuais socialistas e imprensa liberal: o caso Mário } \\
\text { Pedrosa no segundo governo Getúlio Vargas }\end{array}$ & Josnei Di Carlo & UFSC & SC & $\begin{array}{l}\text { Sociologia e } \\
\text { Ciência } \\
\text { Política } \\
\end{array}$ & Dr. & $\begin{array}{l}\text { Ricardo Gaspar } \\
\quad \text { Müller }\end{array}$ \\
\hline 33 & 2019 & $\begin{array}{l}\text { Brasília e Mário Pedrosa: reflexões sobre a crítica da } \\
\text { cidade }\end{array}$ & $\begin{array}{l}\text { Bianca Ardanuy } \\
\text { Abdala }\end{array}$ & UnB & DF & $\begin{array}{l}\text { Arquitetura e } \\
\text { Urbanismo }\end{array}$ & Me. & $\begin{array}{l}\text { Eduardo Pierrotti } \\
\text { Rossetti }\end{array}$ \\
\hline 34 & 2019 & $\begin{array}{l}\text { Abstração e informalismo depois de 1945: de Pedrosa e } \\
\text { Greenberg à nova prosa de Haroldo de Campos }\end{array}$ & $\begin{array}{l}\text { Jorge Manzi } \\
\text { Cembrano }\end{array}$ & USP & SP & $\begin{array}{c}\text { Teoria } \\
\text { Literária e } \\
\text { Literatura } \\
\text { Comparada } \\
\end{array}$ & Dr. & $\begin{array}{l}\text { Jorge Mattos Brito } \\
\text { de Almeida }\end{array}$ \\
\hline 35 & 2019 & $\begin{array}{c}\text { A dimensão afetiva da arte: Mário Pedrosa e a percepção } \\
\text { estética }\end{array}$ & $\begin{array}{l}\text { Gabriela Borges } \\
\text { Abraços }\end{array}$ & USP & SP & $\begin{array}{c}\text { Interunidades } \\
\text { em Estética e } \\
\text { História da } \\
\text { Arte } \\
\end{array}$ & Dr. & $\begin{array}{l}\text { Lisbeth Rebollo } \\
\text { Gonçalves }\end{array}$ \\
\hline 36 & 2020 & $\begin{array}{l}\text { A opção museológica de Mário Pedrosa: solidariedade e } \\
\text { imaginação social em museus da América Latina }\end{array}$ & $\begin{array}{l}\text { Luiza Mader } \\
\text { Paladino }\end{array}$ & USP & SP & $\begin{array}{c}\text { Interunidades } \\
\text { em Estética e } \\
\text { História da } \\
\text { Arte } \\
\end{array}$ & Dr. & $\begin{array}{l}\text { Maria Cristina } \\
\text { Machado Freire }\end{array}$ \\
\hline
\end{tabular}

